\title{
Facial Pain: A Comprehensive Review and Proposal for a Pragmatic Diagnostic Approach
}

\author{
Laura Van Deun ${ }^{a, b}$ Muriel de Witte ${ }^{a, c}$ Thaïs Goessens ${ }^{a, c}$ Stijn Halewyck ${ }^{a, d}$ \\ Marie-Christine Ketelaer ${ }^{a}$ Milica Matic ${ }^{a, e} \quad$ Maarten Moens ${ }^{a}$ f Peter Vaes $^{\text {a, } g}$ \\ Michel Van Lint ${ }^{\mathrm{a}, \mathrm{h}}$ Jan Versijpt ${ }^{\mathrm{a}, \mathrm{b}}$
}

\begin{abstract}
aVrije Universiteit Brussel (VUB), Universitair Ziekenhuis Brussel (UZ Brussel), Headache and Facial Pain Clinic,

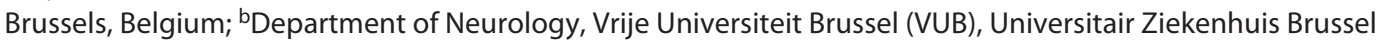

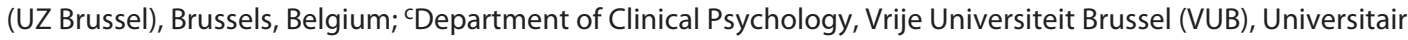
Ziekenhuis Brussel (UZ Brussel), Brussels, Belgium; ${ }^{d}$ Department of Otorhinolaryngology, Vrije Universiteit Brussel (VUB), Universitair Ziekenhuis Brussel (UZ Brussel), Brussels, Belgium; 'Department of Anesthesiology, Vrije Universiteit Brussel (VUB), Universitair Ziekenhuis Brussel (UZ Brussel), Brussels, Belgium; ${ }^{\text {fDepartment of }}$ Neurosurgery, Vrije Universiteit Brussel (VUB), Universitair Ziekenhuis Brussel (UZ Brussel), Brussels, Belgium; ${ }^{9}$ Department of Manual Therapy, Vrije Universiteit Brussel (VUB), Brussels, Belgium; hepartment of Ophthalmology, Vrije Universiteit Brussel (VUB), Universitair Ziekenhuis Brussel (UZ Brussel), Brussels, Belgium
\end{abstract}

\section{Keywords}

Facial pain · Cranial neuralgia - Trigeminal neuralgia ·

Classification · Persistent idiopathic facial pain

\begin{abstract}
Background: Facial pain, alone or combined with other symptoms, is a frequent complaint. Moreover, it is a symptom situated at, more than any other pain condition, a crosspoint where several disciplines meet, for example, dentists; manual therapists; ophthalmologists; psychologists; and ear-nose-throat, pain, and internal medicine physicians besides neurologists and neurosurgeons. Recently, a new version of the most widely used classification system among neurologists for headache and facial pain, the International Classification of Headache Disorders, has been published. Objective: The aims of this study were to provide an overview of the most prevalent etiologies of facial pain and to provide a generic framework for the neurologist on how to
\end{abstract}

karger@karger.com www.karger.com/ene

(C) 2020 S. Karger AG, Base

Karger" manage patients presenting with facial pain. Methods: An overview of the different etiologies of facial pain is provided from the viewpoint of the respective clinical specialties that are confronted with facial pain. Key message: Caregivers should "think outside their own box" and refer to other disciplines when indicated. If not, a correct diagnosis can be delayed and unnecessary treatments might be given. The presented framework is aimed at excluding life- or organthreatening diseases, providing several clinical clues and indications for technical investigations, and ultimately leading to the correct diagnosis and/or referral to other disciplines.

(c) 2020 S. Karger AG, Basel

\section{Introduction}

Facial or orofacial pain refers to any type of pain in the area bounded by the eyes and the lower mandibles, including the oral cavity. Exact prevalence data are 
lacking, although facial pain with or without accompanying symptoms appears to be a very frequent complaint (with population prevalence around 1.9\%) [1]. Women are more frequently affected (women:men ratio 2:1), and other described risk factors are psychological factors, low socioeconomic status, smoking, and the presence of other chronic pain conditions [2]. Virtually all structures in the head and neck region can provoke facial pain. Therefore, more than in other pain syndromes, multiple medical and paramedical disciplines are confronted with facial pain, for example, dentists, manual therapists, ophthalmologists, psychologists, and ear-nose-throat (ENT), pain, and internal medicine physicians in addition to neurologists and neurosurgeons.

Consequently, the differential diagnosis is very broad. Several professional organizations tend to structure the different types of facial pain in classifications, such as the International Headache Society, the International Association for the Study of Pain (IASP), the American Academy of Orofacial Pain, the International Research Diagnostic Criteria for Temporomandibular Dysfunction Consortium Network, and Orofacial Pain Special Interest group of the IASP [3-7]. These classifications differ significantly in taxonomy, illustrating the complexity of this pain condition. The lack of a uniform classification and, therefore, the use of different terms by different disciplines complicate orofacial pain research and the formatting of uniform clinical guidelines [8].

The classification most commonly used by neurologists is the International Classification of Headache Disorders (ICHD). In 2018, a revised classification was published (ICHD-3) [4], including several changes in the classification of facial pain disorders. For the first time, the ICHD criteria are more or less synchronized with the World Health Organization's International Classification of Diseases [3].

This article aims to offer a pragmatic stepwise framework, directed at neurologists in particular, when confronted with facial pain. Its goal is to provide quick-wins and thereby avoid a delay in diagnosis and exclude severe pathologies as soon as possible. This goal can only be reached by a multidisciplinary approach.

First-line treatments with ample clinical evidence are briefly described. More specific and detailed treatment modalities lie beyond the scope of this review.

\section{Facial Pain as Encountered by the Neurologist}

\section{Neuralgias}

Trigeminal neuralgia (TN) is one of the best-known causes of facial pain, though perhaps overdiagnosed. It consists of recurrent unilateral brief electric shock-like pains, abrupt in onset and termination, limited to the distribution of one or more divisions of the trigeminal nerve.

Both TN and cluster headache are considered to be the cause of the most severe pain of neurological origin, hence the term "suicide disease." The lifetime prevalence of TN varies between $0.07 \%$ (primary care record study) and $0.3 \%$ (population study) [9-11]. One study found an unexpectedly high lifetime prevalence of $1.6 \%$, most probably because an older population was sampled [12]. The incidence increases indeed with age, with a typical onset around the sixth decade with a slight female predominance.

The classification of TN underwent important changes throughout the different International Headache Society classifications. In the ICHD-3 beta criteria of 2013 [13], a twofold subdivision was introduced, classical TN (CTN) and painful trigeminal neuropathy (PTN), the latter representing pain in the trigeminal nerve distribution of variable quality and intensity due to neural damage of some sort.

The changes in the recent ICHD-3 criteria were largely influenced by a pivotal study published in 2015 assessing neurovascular conflicts. This prospective magnetic resonance imaging (MRI) study in a large cohort of TN patients evaluated the characteristics of the underlying neurovascular contact [14]. The authors concluded that the mere presence of a neurovascular contact has no clinical significance, as it appears to be equally prevalent on the asymptomatic side. A severe neurovascular contact however, causing displacement or atrophy of the trigeminal nerve, is highly associated with the symptomatic side (prevalence $53 \%$ on the symptomatic side vs. $13 \%$ on the asymptomatic side).

According to the recent ICHD-3 criteria (Fig. 1), the same distinction is made between TN and PTN [15]. TN is further subdivided into CTN (due to an underlying neurovascular compression), secondary TN (due to multiple sclerosis [MS], a space-occupying lesion, or other cause), and idiopathic TN (when there is no evidence for a neurovascular conflict or structural lesion found on imaging or electrophysiological testing). In light of this classification largely driven by neurovascular compression, one should be aware that other potential causes are considered for TN, such as abnormalities of sodium channels 
Fig. 1. ICHD-3 classification of $T N$ and PTN. TN, trigeminal neuralgia; PTN, painful trigeminal neuropathy.

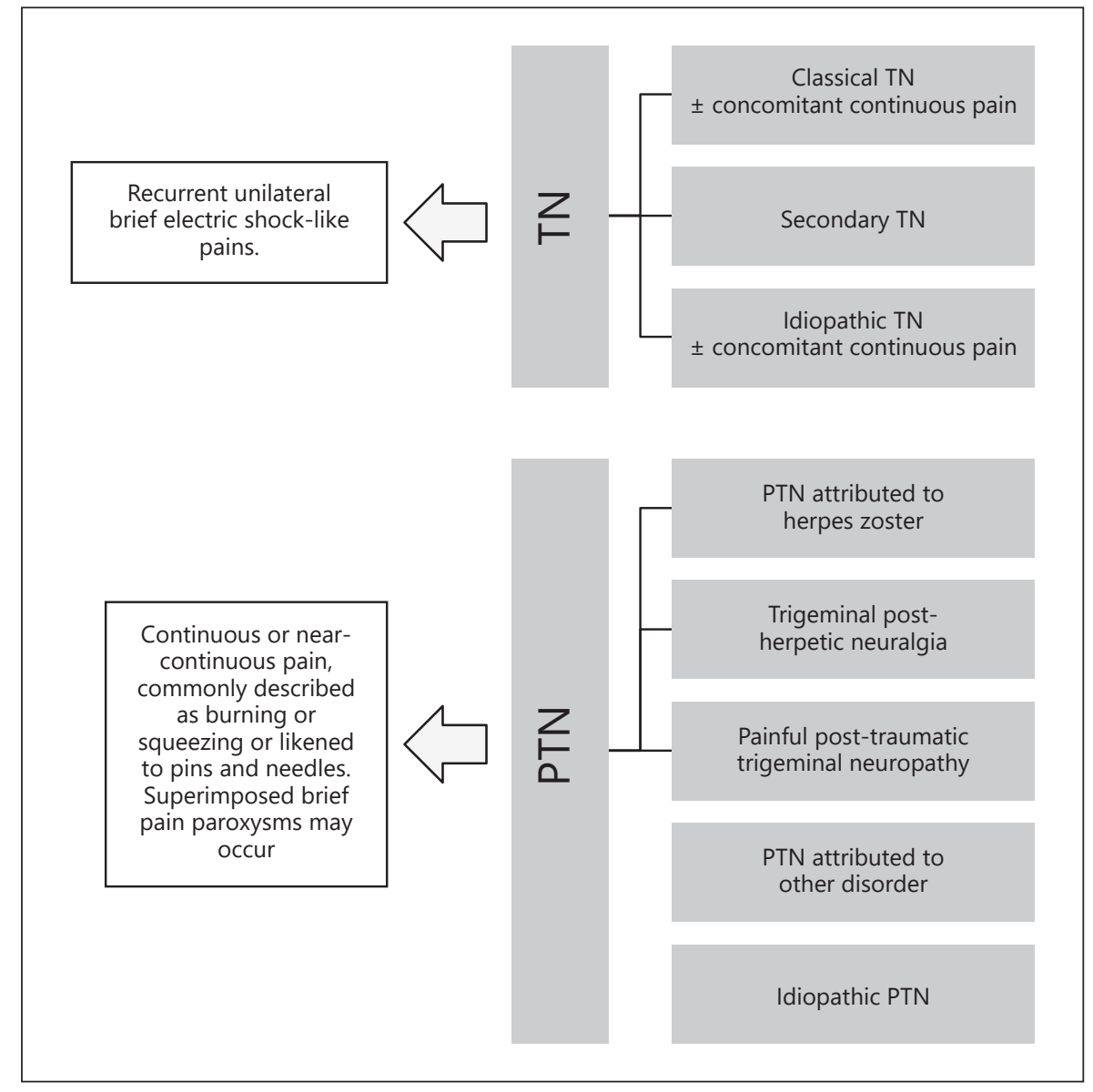

where both an abnormal expression of some voltage-gated sodium channels and a gain-of-function mutation in the sodium channel $\mathrm{Na}_{\mathrm{v}} 1.6$ in a case of $\mathrm{TN}$ were found $[16,17]$.

TN is a clinical diagnosis [15]. According to ICHD-3, it has to concern a severe pain. The pain characteristics are well-defined as abrupt, lasting from a fraction of a second up to $2 \mathrm{~min}$. Often the pain is followed by a refractory period. In most cases, the second or third division of the trigeminal nerve is affected, but a mere involvement of the ophthalmic division is also possible. Additionally, attacks are typically provoked by trigger factors (not only chewing, swallowing, talking, and yawning but also specific scents and flavors) or by contact with trigger zones. Sometimes a background pain persists between attacks, coined by the ICHD as CTN or idiopathic TN with concomitant continuous pain [18].

As mentioned above, only rarely the ophthalmic branch of the trigeminal nerve is involved. In this case, the attacks can be accompanied by mild autonomic symp- toms (tearing and/or red eye), which make them difficult to distinguish from short-lasting unilateral neuralgiform headache attacks with conjunctival injection and tearing (SUNCT) and short-lasting unilateral neuralgiform headache attacks with cranial autonomic symptoms (SUNA).

Structural imaging, by means of 3D high-resolution MRI, must follow a diagnosis of TN. The purpose is, on the one hand, to detect a possible neurovascular conflict and, on the other hand, to exclude a secondary cause. Indeed, in $10-15 \%$ of cases, a causative lesion is identified in the posterior fossa (e.g., a demyelinating or space-occupying lesion). A high index of suspicion for a secondary cause is warranted in case of a sensory deficit or bilateral $\mathrm{TN}$, although a recent study demonstrated that the clinical features of TN patients with or without MS can be indistinguishable [19]. Patients with MS are at risk for developing TN, presumably caused by demyelinating lesions rather than neurovascular compression [20]. Interestingly, a recent imaging study found an association between TN and MS lesions not only in the pontine tri- 
geminal afferents but also in the contralateral insular region and hippocampus [21]. Finally, in some patients with MS-related TN, a demyelinating plaque and neurovascular compression coexist [22].

The treatment of TN differs from that of other neuropathic pain syndromes. Carbamazepine is the first-choice treatment, with an efficacy of around 61\%, although evidence from randomized controlled trials is limited to some small, short-term trials [23]. An alternative is oxcarbazepine, generally better tolerated but with less evidence of efficacy. In patients with a neurovascular conflict and medically refractory $\mathrm{TN}$, microvascular decompression is generally the most successful option, with about $75 \%$ of the patients being pain free up to 5 years after surgery and a relatively low recurrence rate (about $4 \%$ per year) [2426]. Perioperative morbidity cannot be underestimated since it involves an open cranial operation; however, this risk has to be outweighed against the substantial impact this devastating disease has on daily life, with severe depression being present in more than $10 \%$ of the patients $[27,28]$. Other less invasive treatment options are radiofrequency rhizotomy, glycerol rhizotomy, balloon microcompression, and stereotactic radiosurgery (gamma knife). These techniques are all more or less destructive, which means the sensory fibers are damaged to a greater or lesser extent. Facial numbness is the most common side effect, although it tends to improve with time. Success rate is lower and the recurrence rate higher than those of microvascular decompression [29]. For a treatment algorithm, we further refer to a recently published review article and an even more recent guideline of the European Academy of Neurology [30, 31].

PTN is clinically characterized by a more constant burning sensation in the trigeminal area and may be accompanied by sensory changes in this area or even weakness in the masticatory muscles. The exact prevalence remains unclear, partly due to the widespread variety in terminology. This syndrome is by definition due to a secondary cause and, therefore, warrants an extensive search for an underlying etiology [32]. Trauma appears to be the most common cause of PTN. Indeed, both large craniofacial traumas and small dental interventions can lead to a painful intra- or extraoral trigeminal neuropathy. Other causes can be neoplastic (e.g., masses around the cerebellopontine angle), vascular (e.g., brainstem hemorrhage or infarction), or inflammatory (e.g., connective tissue disease). For an interesting review on trigeminal neuropathy, we refer to Smith and Cutrer [32].

ICHD-3 further withholds 3 other, less common, cranial neuralgias leading to facial pain. These cranial neural- gias share similar pain characteristics, but in a different localization. Glossopharyngeal neuralgia causes brief electric pain episodes in the ear, base of the tongue, tonsillar fossa, and/or beneath the angle of the jaw, typically triggered by swallowing. In case of involvement of the vagus nerve, patients can develop bradycardia, syncope, and even asystole during pain attacks. In $10-12 \%$, there is a coexistent TN [33]. In analogy with the TN classification, ICHD-3 distinguishes glossopharyngeal neuralgia from painful glossopharyngeal neuropathy. Nervus intermedius neuralgia presents with neuropathic pain in the ear canal. Painful nervus intermedius neuropathy is a more continuous pain, occurring sometimes in the context of a herpes zoster infection.

Occipital neuralgia is also mentioned as a cause of facial pain, since the pain of occipital neuralgia may in rare cases reach the fronto-orbital area through trigeminocervical connections [34].

When there is a suspicion of any facial neuralgia, imaging by means of high-resolution MRI is warranted in search of secondary causes or vascular conflicts. The meaning of these neurovascular conflicts has, however, only been formally validated in TN.

\section{Primary Headache Disorders Presenting as Facial Pain}

Considering the differential diagnosis of a brief episodic unilateral pain in the trigeminal area, it is important to take into account some of the trigeminal autonomic cephalalgias (TACs). TACs are classified mainly based on the duration of symptoms. As mentioned above, SUNCT/SUNA mostly occur in the first distribution of the trigeminal nerve; however, they can also occur in the second or third division. The typically associated profound cranial autonomic symptoms, the occurrence of pain in a sawtooth pattern or as multiple stabs, as well as the lack of a refractory period, can help distinguish these syndromes from TN $[35,36]$. SUNCT/SUNA are, although a matter of debate, considered primary headache disorders; however, secondary cases are increasingly being described in the literature, for example, due to neurovascular conflicts, white matter lesions, and pituitary lesions $[37,38]$. Treatment of SUNCT/SUNA differs from that of TN or other TACs with lamotrigine, topiramate, and gabapentin as the preferred preventive treatment medications [39-42]. The first-line treatment for SUNCT/ SUNA exacerbations is intravenous lidocaine. In addition, patients with SUNCT/SUNA and a trigeminal neurovascular conflict on brain imaging might benefit from microvascular decompression, although the evidence is very limited $[43,44]$. 
Cluster headache, paroxysmal hemicrania, or hemicrania continua can also present with unilateral facial pain. Here, the distinction from TN is more readily made, as the pain episodes last longer. Nonetheless, cluster headache is often interpreted as of dental origin and treated likewise [45]. The response to treatment can be helpful in the differential diagnosis. In cluster headache, a response to oxygen or triptans can be informative. Regarding hemicrania continua and paroxysmal hemicrania, the response to indomethacin is mandatory.

Although "facial migraine" is not formally considered as a diagnostic entity, it is a known fact that migraine can present as a combination of head and facial pain, or even as mere facial pain [46-48].

\section{Cervicogenic Headache and Facial Pain}

It is generally accepted that disorders of the cervical spine can provoke head or facial pain [49]. Prevalence ranges from 0.4 to $4.1 \%$, with women being more affected than men [50-52]. Apart from the diagnostic criteria in the ICHD-3, the Cervicogenic Headache International Study Group also proposed more detailed diagnostic criteria [53]. Cervicogenic headache is mostly unilateral, with the unique characteristic of originating posteriorly and radiating to the frontal and orofacial regions. Pain is provoked by certain movements or prolonged positions of the neck. Cervical manipulation can reproduce the pain, whereas the blockade of a cervical structure or its nerve supply abolishes the pain. Possible causes of cervicogenic head or facial pain are, among others, rheumatoid arthritis, cervical dystonia, and tumors in the neck region. There has been some debate about whether cervical disc disease is considered a cause of cervicogenic head or facial pain. ICHD-3 mentions cervical spondylosis as a possible cause of cervicogenic headache, while headache caused by upper cervical radiculopathy is only included in the appendix. On the other hand, data from small observational studies suggest that the vast majority of patients with cervicogenic headache due to (upper) cervical disc disease benefit from cervical disc surgery [54, 55]. Obviously, the diagnosis of cervicogenic headache, on the one hand, and treatment, on the other hand, warrant a multidisciplinary approach, preferably including a manual therapist, neurosurgeon, and anesthesiologist.

\section{Persistent Idiopathic Facial Pain}

Persistent idiopathic facial pain (PIFP), formerly termed atypical facial pain, is a diagnosis of exclusion. Patients present with a dull, aching, or nagging orofacial pain at least $2 \mathrm{~h}$ daily since at least 3 months [56]. There are no clinical neurological deficits, and a dental cause has to be excluded. The onset of pain is often associated with (minor) dental, ENT, or other surgical procedures where pain persists after healing of the initial noxious event without any demonstrable local cause, nor does the pain follow the distribution of a peripheral nerve. Women are more frequently affected than men. Often other pain syndromes and mood disorders coexist, resulting in an important psychosocial burden. Although considered as a diagnosis of exclusion, a positive diagnosis of PIFP could bring on a feeling of acknowledgment and relief.

\section{Central Causes of Facial Pain}

In ICHD-3, 2 types of central neuropathic pain are explicitly mentioned as a cause of facial pain, namely, central neuropathic pain attributed to MS and central poststroke pain[57-61]. In both entities, a lesion of the ascending pathways of the trigeminal nuclei is mostly the cause, next to damage to the cervical spinothalamic pathways or cortical processing areas. Another cause of facial pain is cervical carotid or vertebral artery dissection [62]. The facial pain is usually ipsilateral to the side of the dissected vessel and mostly of sudden onset. An interesting entity is paratrigeminal oculosympathetic (Raeder's) syndrome, where the combination of facial pain in the ophthalmic region as well as ipsilateral miosis and ptosis warrants a search for disease of the carotid artery or surrounding paratrigeminal structures [63]. While not explicitly mentioned as a cause of facial pain in ICHD-3, in select patients cerebral ischemic events, hemorrhages, and vascular malformations, as well as pituitary apoplexy, can present with facial pain [64].

\section{Rare Syndromes}

Eagle syndrome is a rare disorder due to inflammation of the stylohyoid ligament [65]. Pain can be situated in the head or neck region, but pharyngeal and facial pain is also possible. Turning of the head typically provokes the pain. Furthermore, clinical examination can confirm the diagnosis if pain is provoked by oral palpation of the tonsillar fossa or if a hard process is palpated. On the other hand, pain is improved by injection of a local anesthetic agent into the stylohyoid ligament, or by styloidectomy. Imaging reveals calcification or elongation of the stylohyoid ligament. Another rare disorder characterized by symptoms after head turning is the neck-tongue syndrome. Turning of the neck provokes unilateral neck and/or occipital pain, as well as an abnormal sensation and/or posture of the ipsilateral tongue [66]. 
Facial Pain as Encountered by the Stomatologist and Dentist

\section{Temporomandibular Disorders}

Temporomandibular disorders (TMD) are a group of musculoskeletal and neuromuscular disorders of multifactorial origin, involving the temporomandibular joints (TMJs) and the masticatory muscles.

Patients typically present with unilateral facial pain in the preauricular area, often worsened by movement or palpation of the TMJs or surrounding masticatory muscles. The pain is usually dull, with superimposed sharper shooting pains. Other symptoms and clinical signs may be (temporal) headache, limitation of the range of mandibular motion, deviation of the mandible on jaw opening, tenderness with palpation of the TMJs and masticatory muscles, and abnormal joint sounds (clicking).

In 2014, the International Research Diagnostic Criteria for Temporomandibular Dysfunction Consortium Network and the Orofacial Pain Special Interest Group of the IASP suggested an updated classification of TMD called the Diagnostic Criteria for Temporomandibular Disorders [67]. Common types of TMD include myalgia, arthralgia, and headache attributed to TMD, as well as temporomandibular disc displacements and degenerative joint disease.

Pain in the TMJ region is very common, with a prevalence of about $5-15 \%$ in the general population and an incidence of $4 \%$ in a large cohort of adults [68-70]. Women are at least twice more affected than men. Interestingly, the Diagnostic Criteria for Temporomandibular Disorders classification system consists of 2 axes: a physical and a psychosocial axis. Indeed, TMD are often associated with, for example, mood disorders. Other risk factors are bruxism, certain genetic factors, migraine, tension-type headache, other chronic pain conditions, and a history of trauma, as described in the longitudinal OPPERA study [71-75]. Whether an aberrant dental occlusion is a risk factor for TMD is still debated, although the existing evidence shows no clear-cut association between TMD symptoms or signs and malocclusion [76, 77].

In most cases, conservative management with behavioral, physical (e.g., jaw exercises), or occlusal appliance therapy or pharmacotherapy is sufficient. Rarely, surgical therapy is necessary. Overall, the evidence for all treatment modalities in TMD is very scarce [78-82].

\section{Dental Pain and Diseases of the Oral Mucosa}

Pain originating in the teeth and surrounding structures is without doubt the most common cause of lower orofacial pain. Nevertheless, many patients with oral pain of non-dental origin are given unnecessary dental treatments. In some cases, there are evident clues leading to a dental origin and ensuing referral to a dentist or stomatologist: redness and other signs of inflammation in the oral cavity, or pain provoked by intake of hot or cold substances. Pressure pain on the tooth is also revealing for a dental etiology. The possible etiologies are numerous, for example, pulpitis, periapical periodontitis, and cracked tooth syndrome [83].

Atypical odontalgia, or, the recent and probably more correct term, persistent dentoalveolar pain, is a term commonly used by dentists and stomatologists for pain in a tooth region without clinical or radiological evidence for disease. Often the onset is related to a previous dental treatment. ICHD-3 mentions atypical odontalgia as a probable subgroup of PIFP. The importance of acknowledging this syndrome is mainly in preventing unnecessary and possibly worsening dental treatment for this condition which exerts a significant biopsychosocial impact on the individual $[84,85]$.

Diseases of the oral mucosa are also numerous, for example, malignancies and diverse inflammatory diseases. A careful clinical examination and directed radiological examination often lead to the correct diagnosis [83].

\section{Salivary Gland Disorders}

Disease of a salivary gland can cause severe lower facial pain, which typically occurs preprandial and during the meal. Causes of such disorders are most commonly duct blockage, tumors, or infections [86, 87].

\section{Burning Mouth Syndrome}

Burning mouth syndrome (BMS) is a rare disorder characterized by daily symptoms (at least $2 \mathrm{~h}$ daily in the last 3 months) of a neuropathic burning pain sensation at the level of the superficial oral mucosa. The most frequent pain localization is the tip of the tongue. Dryness of the tongue and a change in taste are also reported, but clinical examination reveals no abnormalities [88]. The affected patients are mostly peri- or postmenopausal women, and there is a clear association with psychological comorbidities. Interestingly, the unstimulated salivary flow rate has been found to be lower in patients with BMS [89-92].

Evidence on treatment is scarce [93]. Suggested treatments are cognitive behavioral therapy in which the patient is also reassured and the, most probably, neuropathic etiology of this condition is acknowledged next to antidepressants or drugs used for neuropathic pain, and
Van Deun et al. 
topical therapies. The prognosis is reserved; in only a minority of cases, a restitutio ad integrim is accomplished.

In ICHD-3, the term BMS is reserved for idiopathic cases, without an underlying cause. Evidently, numerous local and systemic diseases as well as medications can provoke similar symptoms, for example, local infections, Sjögren's syndrome, and diabetes. In this case, often the term secondary BMS is used, but in ICHD-3 this term is not included.

\section{Facial Pain as Encountered by ENT Physicians, Ophthalmologists, Internal Medicine Physicians, or Other Caregivers}

\section{Giant Cell Arteritis}

In every patient older than 50 years presenting with head or facial pain, the diagnosis of giant cell arteritis (GCA) should be considered. GCA is a vasculitis of the medium and large arteries, involving the aorta and its branches with a predisposition for the cranial branches of the external carotid and ophthalmic branches of the internal carotid artery [94]. GCA occurs mostly in the elderly Caucasian population, with a north-south gradient and a higher prevalence in women [95]. GCA is a medical emergency, since it may lead to irreversible visual impairment, stroke, and even death if left untreated.

A patient is considered to have GCA when fulfilling at least three of the following 5 criteria: age at onset older than 50 years, new headache, abnormality of the temporal artery (tenderness, reduced pulsation, redness, or swelling), an erythrocyte sedimentation rate above $50 \mathrm{~mm} / \mathrm{h}$, and an abnormal temporal artery biopsy [96]. Although GCA often presents with a myriad of other symptoms and signs (systemic, respiratory, vascular, or dermatological), in some cases the only complaint is head or facial pain. The pain is nonspecific in terms of quality and onset, and is temporal in about $25-50 \%$ of patients $[97,98]$. The pain might also be located around the TMJs during chewing (jaw claudication), often leading to a misdiagnosis of TMD [99]. The pain associated with jaw claudication typically begins with a latency after heavy chewing and is localized around the masticatory muscles rather than the TMJs [100]. Treatment should be started promptly, and a prolonged treatment with steroids and/or other immunosuppressive agents is often necessary. After discontinuation of steroids, a high recurrence rate exists in up to half of the patients [101]. More recently, the role of biological therapies such as monoclonal antibodies was explored [102].
Table 1. Initial assessment of patients with facial pain

\begin{tabular}{|c|c|}
\hline History & \\
\hline Patient characteristic & Age, race, gender, medical history \\
\hline Pain & $\begin{array}{l}\text { Timing (periodicity and duration) } \\
\text { Location and radiation } \\
\text { Severity and quality } \\
\text { Relieving and aggravating factors, } \\
\text { for example, sleep } \\
\text { Impact on daily life }\end{array}$ \\
\hline $\begin{array}{l}\text { Associated symptoms } \\
\text { and conditions }\end{array}$ & $\begin{array}{l}\text { Headache and/or migrainous features } \\
\text { Neurological symptoms } \\
\text { ENT symptoms } \\
\text { Eye symptoms } \\
\text { TMD symptoms } \\
\text { Systemic symptoms } \\
\text { Chronic pain conditions }\end{array}$ \\
\hline Clinical examination & \\
\hline $\begin{array}{l}\text { Neurological and clinical } \\
\text { examination }\end{array}$ & $\begin{array}{l}\text { Complete neurological examination } \\
\text { including fundoscopy } \\
\text { Mouth, throat, nose, ear, and eye } \\
\text { examination, including exploration of } \\
\text { the trochlear area } \\
\text { TMJ palpation } \\
\text { Temporal arteries inspection and } \\
\text { palpation } \\
\text { Cervical manipulation }\end{array}$ \\
\hline
\end{tabular}

\section{Rhinosinusitis}

Rhinosinusitis is often considered as a cause of head or facial pain. This entity might however be overestimated, also influenced by the frequent reporting of sinusitis on brain imaging. Less than $10 \%$ of the patients considering their head or facial pain as "sinus related" will eventually be diagnosed with rhinosinusitis after a thorough workup [103]. In the other $90 \%$, the final diagnosis is mostly migraine. Several factors lead to this difficult differential diagnosis between rhinosinusitis and migraine, illustrated by the aphorism "guilt by provocation, location, and association" [104]. Indeed, migraine can also be provoked by weather changes, can also present with mere facial pain, and can also be associated with autonomic symptoms such as nasal congestion or a runny nose. In patients with sinusitis, nose symptomatology is generally present, where loss of smell can also be a discriminating factor [105].

\section{Ophthalmological Disorders}

Ophthalmologists are often consulted in case of facial (mostly periorbital) pain. However, only in a minority of cases an ophthalmological cause can be found. 


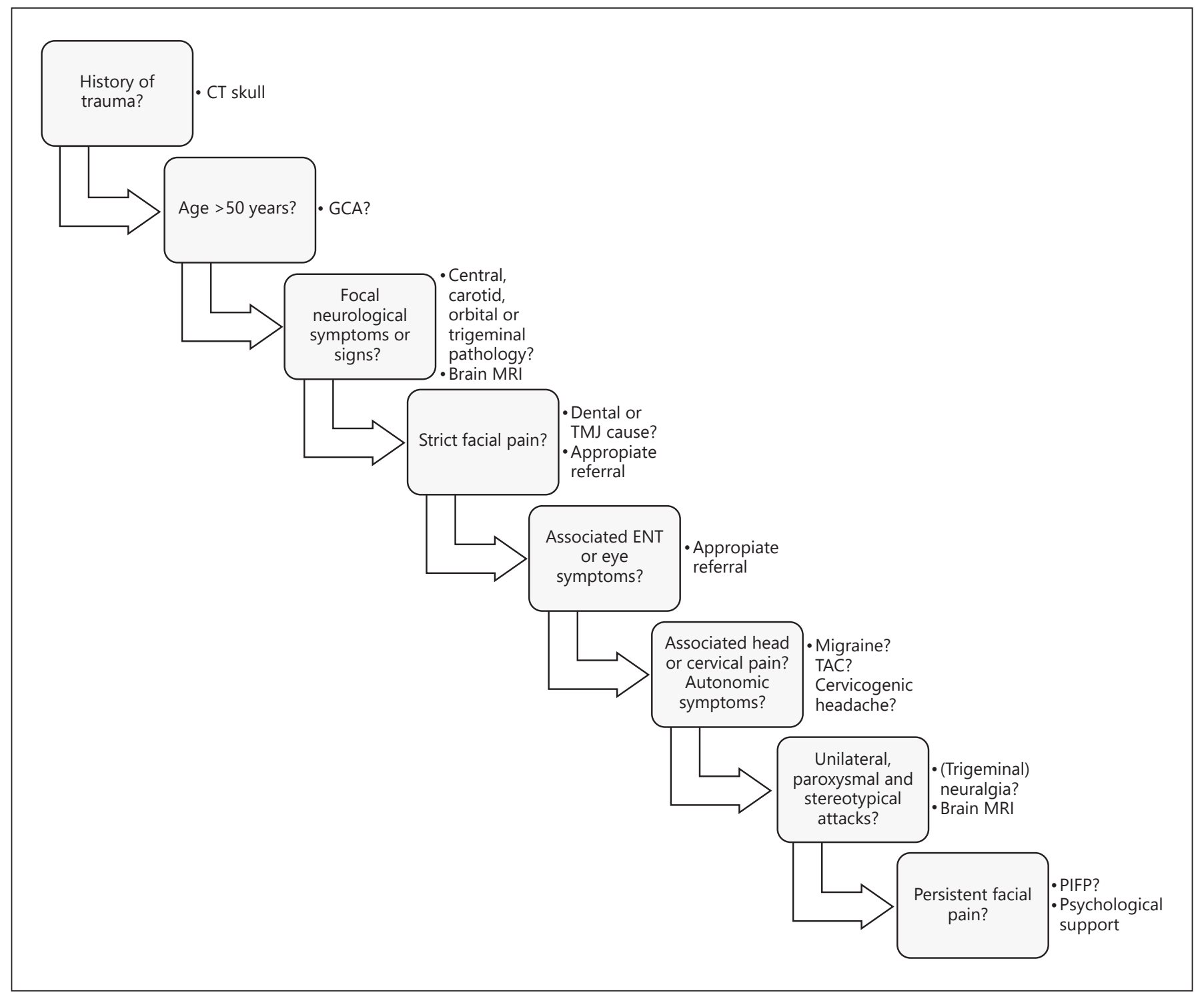

Fig. 2. Multistep generic approach to facial pain taking into account certain findings from history or clinical examination (boxes) aimed mainly at excluding life- or organ-threatening disorders and more oriented investigations/referrals and treatment strategies.
CT, computed tomography; GCA, giant cell arteritis; MRI, magnetic resonance imaging; TMJ, temporomandibular joint; ENT, ear-nose-throat; TAC, trigeminal autonomic cephalalgia; PIFP, persistent idiopathic facial pain.
Head or facial pain is often attributed to refractive error or strabismus, but only in a few cases, mainly children, these disorders are actually responsible for the complaints [106]. One should be attentive not to miss ophthalmological emergencies, such as acute angle-closure glauco$m a$. The latter may present with ipsilateral facial pain, visual impairment, and nausea or vomiting $[107,108]$, and with a potentially devastating outcome if left untreated. Ocular ischemic syndrome, due to severe carotid occlusive disease, can also present with, next to visual loss, perior- bital pain [109]. Another cause of eye-related facial pain is optic neuritis. Optic neuritis occurs mostly in otherwise healthy, young adults, with a female preponderance. Orbital pain is worsened by eye movements, and there is (sub)acute loss of visual acuity and color vision. The diagnosis is clinical, if indicated, followed by radiological, electrophysiological, and laboratory examinations. Trochlear headache is a pain disorder in which trochlear inflammation (trochleitis) or dysfunction causes periorbital pain or frontal headache. A provocative maneuver 
with exploration of the trochlear area can confirm the diagnosis [110]. Recurrent painful ophthalmoplegic neuropathy, formerly called ophthalmoplegic migraine [111], is an interesting but rare disorder characterized by recurrent attacks of ocular cranial nerve palsies (most often the oculomotor nerve) with ipsilateral head or facial pain. The pain develops up to 2 weeks before ophthalmoparesis, and the pain features and accompanying symptoms resemble migraine. A similar condition presenting with unilateral (peri)orbital pain associated with paresis of one or more of the third, fourth, and/or sixth cranial nerve is the Tolosa-Hunt syndrome, caused by a granulomatous inflammation in the cavernous sinus, superior orbital fissure, or orbit [112].

Other causes of eye-related facial pain are ocular inflammatory diseases such as iritis, uveitis, cyclitis, scleritis, choroiditis, conjunctivitis, and corneal inflammation, as well as ischemic ocular motor nerve palsies.

\section{A Practical Approach to Facial Pain}

When assessing facial pain, the first and most important step is a thorough history, usually leading to a substantial narrowing of the possible differential diagnoses. Next, the neurological examination might reveal directional signs. Table 1 illustrates important elements of this workup. Then, depending on the remaining possible diagnoses, technical investigations can be ordered to confirm a diagnosis or exclude others.

Figure 2 displays a framework for the assessment of facial pain, in which the associated symptoms and pain characteristics are of primary interest. The intention of the presented scheme is not to cover all potential etiologies of orofacial pain but rather, by progressing through the scheme, to narrow the differential diagnosis and orient diagnostic examinations. An alternative approach to differentiate separate orofacial pain entities based on timing and lateralization can be found in another excellent review article [113].

\section{Conclusions}

When confronted with facial pain, a multidisciplinary approach is mandatory. The use of a uniform terminology according to a validated classification and a structured workup when assessing a patient with facial pain is recommended.

\section{Acknowledgements}

The authors would like to thank Koen Paemeleire for his critical, inspiring, and thought-provoking comments concerning this manuscript.

\section{Statement of Ethics}

This study complies with internationally accepted standards for research practice and reporting.

\section{Disclosure Statement}

The authors have no conflicts of interest to declare.

\section{Funding Sources}

Not applicable for this study.

\section{Author Contributions}

All authors discussed the manuscript, revised it critically for important intellectual content, and approved the final version. Jan Versijpt and Laura Van Deun take responsibility for the integrity of the work as a whole, from inception to publication of the article.

\section{References}

1 Macfarlane TV, Beasley M, Macfarlane GJ. Self-reported facial pain in UK biobank study: prevalence and associated factors. J Oral Maxillofac Res. 2014 Jul;5(3):e2.

2 Svensson P, Kumar A. Assessment of risk factors for oro-facial pain and recent developments in classification: implications for management.JOral Rehabil.2016Dec;43(12):97789.

3 Benoliel R, Svensson P, Evers S, Wang S-J, Barke A, Korwisi B, et al. The IASP classifica- tion of chronic pain for ICD-11: chronic secondary headache or orofacial pain. Pain. 2019 Jan;160(1):60-8.

4 Headache Classification Committee of the International Headache Society (IHS). The international classification of headache disorders, 3rd edition. Cephalalgia. 2018 Jan; $38(1): 1-211$.

5 Schiffman E, Ohrbach R, Truelove E, Look J, Anderson G, Goulet J-P, et al. Diagnostic criteria for temporomandibular disorders (DC/
TMD) for clinical and research applications: recommendations of the international RDC/ TMD Consortium Network and orofacial pain special interest group. J Oral Facial Pain Headache. 2014;28(1):6-27.

6 Sessle BJ, editor. Orofacial pain. Washington, DC: IASP Press; 2014

7 De Leeuw R, Klasser GD. Orofacial pain: guidelines for assessment, diagnosis, and management. 5th ed. Chicago, IL: Quintessence Publishing; 2013. 
8 Svensson P, May A. Classification: the key to understanding facial pain. Cephalalgia. 2017 Apr;37(7):609-12.

9 Sjaastad O, Bakketeig LS. The rare, unilateral headaches. Vågå study of headache epidemiology. J Headache Pain. 2007 Feb;8(1):19-27.

10 Mueller D, Obermann M, Yoon M-S, Poitz F, Hansen N, Slomke M-A, et al. Prevalence of trigeminal neuralgia and persistent idiopathic facial pain: a population-based study. Cephalalgia. 2011 Nov;31(15):1542-8.

11 MacDonald BK, Cockerell OC, Sander JW, Shorvon SD. The incidence and lifetime prevalence of neurological disorders in a prospective community-based study in the UK. Brain. 2000 Apr;123(Pt 4):665-76.

12 Schwaiger J, Kiechl S, Seppi K, Sawires M, Stockner H, Erlacher T, et al. Prevalence of primary headaches and cranial neuralgias in men and women aged 55-94 years (Bruneck Study). Cephalalgia. 2009 Feb;29(2):179-87.

13 Headache Classification Committee of the International Headache Society (IHS). The international classification of headache disorders, 3rd edition (beta version). Cephalalgia. 2013 Jul;33(9):629-808.

14 Maarbjerg S, Wolfram F, Gozalov A, Olesen J, Bendtsen L. Significance of neurovascular contact in classical trigeminal neuralgia. Brain. 2015 Feb;138(2):311-9.

15 Cruccu G, Finnerup NB, Jensen TS, Scholz J, Sindou M, Svensson P, et al. Trigeminal neuralgia: new classification and diagnostic grading for practice and research. Neurology. 2016 Jul;87(2):220-8

16 Tanaka BS, Zhao P, Dib-Hajj FB, Morisset V, Tate S, Waxman SG, et al. A gain-of-function mutation in Nav1.6 in a case of trigeminal neuralgia. Mol Med. 2016 Sep;22:338-48.

17 Siqueira SRDT, Alves B, Malpartida HMG, Teixeira MJ, Siqueira JTT. Abnormal expression of voltage-gated sodium channels Nav1.7, Nav1.3 and Nav1.8 in trigeminal neuralgia. Neuroscience. 2009 Dec;164(2):573-7.

18 Maarbjerg S, Gozalov A, Olesen J, Bendtsen L. Concomitant persistent pain in classical trigeminal neuralgia - evidence for different subtypes. Headache J Head Face Pain. 2014 Jul; 54(7):1173-83.

19 Godazandeh K, Martinez Sosa S, Wu J, Zakrzewska JM. Trigeminal neuralgia: comparison of characteristics and impact in patients with or without multiple sclerosis. Mult Scler Relat Disord. 2019 Sep;34:41-6.

20 Cruccu G, Biasiotta A, Di Rezze S, Fiorelli M, Galeotti F, Innocenti P, et al. Trigeminal neuralgia and pain related to multiple sclerosis. Pain. 2009 Jun;143(3):186-91.

21 Fröhlich K, Winder K, Linker RA, Engelhorn T, Dörfler A, Lee D-H, et al. Supratentorial lesions contribute to trigeminal neuralgia in multiple sclerosis. Cephalalgia. 2018 Jun;38(7):1326-34.

22 Truini A, Prosperini L, Calistri V, Fiorelli M, Pozzilli C, Millefiorini E, et al. A dual concurrent mechanism explains trigeminal neuralgia in patients with multiple sclerosis. Neurology. 2016 May;86(22):2094-9.
23 Wiffen PJ, Derry S, Moore RA, Kalso EA. Carbamazepine for chronic neuropathic pain and fibromyalgia in adults. Cochrane Database Syst Rev. 2014 Apr;(4):CD005451. .

24 Jannetta PJ. Arterial compression of the trigeminal nerve at the pons in patients with trigeminal neuralgia. J Neurosurg. 1967 Jan;26(1 Pt 2):159-62.

25 Barker FG, Jannetta PJ, Bissonette DJ, Larkins MV, Jho HD. The long-term outcome of microvascular decompression for trigeminal neuralgia. N Engl J Med. 1996 Apr;334(17): 1077-84.

26 Zakrzewska JM, Coakham HB. Microvascular decompression for trigeminal neuralgia: update. Curr Opin Neurol. 2012 Jun;25(3):296301.

27 Kalkanis SN, Eskandar EN, Carter BS, Barker FG, Bricolo A, Casey KF, et al. Microvascular decompression surgery in the United States, 1996-2000: mortality rates, morbidity rates, and the effects of hospital and surgeon volumes. Neurosurgery. 2003 Jun;52(6):125162.

28 Zakrzewska JM, Wu J, Mon-Williams M, Phillips N, Pavitt SH. Evaluating the impact of trigeminal neuralgia. Pain. 2017;158(6):116674.

29 Zakrzewska JM, Akram H. Neurosurgical interventions for the treatment of classical trigeminal neuralgia. Cochrane Database Syst Rev. 2011 Sep;(9):CD007312.

30 Bendtsen L, Zakrzewska JM, Abbott J, Braschinsky M, Di Stefano G, Donnet A, et al. European Academy of Neurology guideline on trigeminal neuralgia. Eur J Neurol. 2019 Jun;26(6):831-49.

31 Cruccu G. Trigeminal neuralgia. Contin Lifelong Learn Neurol. 2017 April;23(2):396-420.

32 Smith JH, Cutrer FM. Numbness matters: a clinical review of trigeminal neuropathy. Cephalalgia. 2011 Jul;31(10):1131-44.

33 Rushton JG, Stevens JC, Miller RH. Glossopharyngeal (vagoglossopharyngeal) neuralgia A study of 217 cases. Arch Neurol. 1981 Apr;38(4):201-5.

34 Bartsch T, Goadsby PJ. Anatomy and physiology of pain referral patterns in primary and cervicogenic headache disorders. Headache Curr. 2005 Mar;2(2):42-8.

35 Benoliel R, Sharav Y, Haviv Y, Almoznino G. Tic, triggering, and tearing: from CTN to SUNHA. Headache J Head Face Pain. 2017 Jun;57(6):997-1009.

36 Paliwal VK, Singh P, Kumar A, Rahi SK, Gupta RK. Short-lasting unilateral neuralgiform headache with conjunctival injection and tearing (SUNCT) with preserved refractory period: report of three cases. J Headache Pain. 2012 Mar;13(2):167-9.

37 Cohen AS, Matharu MS, Goadsby PJ. Shortlasting unilateral neuralgiform headache attacks with conjunctival injection and tearing (SUNCT) or cranial autonomic features (SUNA) - a prospective clinical study of SUNCT and SUNA. Brain. 2006 Oct;129(10): 2746-60.
38 Williams M, Bazina R, Tan L, Rice H, Broadley SA. Microvascular decompression of the trigeminal nerve in the treatment of SUNCT and SUNA. J Neurol Neurosurg Psychiatry. 2010 Sep;81(9):992-6.

39 Pareja JA, Álvarez M. The usual treatment of trigeminal autonomic cephalalgias. Headache J Head Face Pain. 2013 Oct;53(9):1401-14.

40 Baraldi C, Pellesi L, Guerzoni S, Cainazzo MM, Pini LA. Therapeutical approaches to paroxysmal hemicrania, hemicrania continua and short lasting unilateral neuralgiform headache attacks: a critical appraisal. J Headache Pain. 2017 Dec;18(1):71.

41 Cohen A. SUN: short-lasting unilateral neuralgiform headache attacks. Headache J Head Face Pain. 2017 Jun;57(6):1010-20.

42 Weng H-Y, Cohen AS, Schankin C, Goadsby PJ. Phenotypic and treatment outcome data on SUNCT and SUNA, including a randomised placebo-controlled trial. Cephalalgia. 2018 Aug;38(9):1554-63.

43 Favoni V, Grimaldi D, Pierangeli G, Cortelli P, Cevoli S. SUNCT/SUNA and neurovascular compression: new cases and critical literature review. Cephalalgia. 2013 Dec;33(16): 1337-48.

44 Hassan S, Lagrata S, Levy A, Matharu M, Zrinzo L. Microvascular decompression or neuromodulation in patients with SUNCT and trigeminal neurovascular conflict? Cephalalgia. 2018 Feb;38(2):393-8.

45 Bahra A, Goadsby PJ. Diagnostic delays and mis-management in cluster headache. Acta Neurol Scand. 2004 Mar;109(3):175-9.

46 Daudia AT, Jones NS. Facial migraine in a rhinological setting. Clin Otolaryngol Allied Sci. 2002 Dec;27(6):521-5.

47 Obermann M, Mueller D, Yoon MS, Pageler L, Diener HC, Katsarava Z. Migraine with isolated facial pain: a diagnostic challenge. Cephalalgia. 2007 Nov;27(11):1278-82.

48 Yoon MS, Mueller D, Hansen N, Poitz F, Slomke M, Dommes P, et al. Prevalence of facial pain in migraine: a population-based study. Cephalalgia. 2010 Jan;30(1):92-6.

49 Fredriksen TA, Hovdal H, Sjaastad O. "Cervicogenic headache": clinical manifestation. Cephalalgia. 1987 Jun;7(2):147-60.

50 Leone M, D’Amico D, Grazzi L, Attanasio A, Bussone G. Cervicogenic headache: a critical review of the current diagnostic criteria. Pain. 1998 Oct;78(1):1-5.

51 Sjaastad O, Bakketeig LS. Prevalence of cervicogenic headache: Vågå study of headache epidemiology. Acta Neurol Scand. 2008 Mar; 117(3):173-80.

52 Antonaci F, Sjaastad O. Cervicogenic headache: a real headache. Curr Neurol Neurosci Rep. 2011 Apr;11(2):149-55.

53 Sjaastad O, Fredriksen TA, Pfaffenrath V. Cervicogenic headache: diagnostic criteria. Headache J Head Face Pain. 1998 Jun;38(6): 442-5. 
54 Diener HC, Kaminski M, Stappert G, Stolke D, Schoch B. Lower cervical disc prolapse may cause cervicogenic headache: prospective study in patients undergoing surgery. Cephalalgia. 2007 Sep;27(9):1050-4.

55 Schofferman J, Garges K, Goldthwaite N, Koestler M, Libby E. Upper cervical anterior diskectomy and fusion improves discogenic cervical headaches. Spine. 2002 Oct;27(20): 2240-4.

56 Benoliel R, Gaul C. Persistent idiopathic facial pain. Cephalalgia. 2017 Jun;37(7):680-91.

57 Klit H, Finnerup NB, Jensen TS. Central poststroke pain: clinical characteristics, pathophysiology, and management. Lancet Neurol. 2009 Sep;8(9):857-68.

58 Kalita J, Kumar B, Misra UK, Pradhan PK. Central post stroke pain: clinical, MRI, and SPECT correlation. Pain Med. 2011 Feb; 12(2):282-8.

59 Hong JH, Bai DS, Jeong JY, Choi BY, Chang $\mathrm{CH}$, Kim SH, et al. Injury of the spino-thalamo-cortical pathway is necessary for central post-stroke pain. Eur Neurol.2010;64(3):163-

60 Österberg A, Boivie J. Central pain in multiple sclerosis - sensory abnormalities. Eur J Pain. 2010 Jan;14(1):104-10.

61 Österberg A, Boivie J, Thuomas K-Å. Central pain in multiple sclerosis - prevalence and clinical characteristics. Eur J Pain. 2005 Oct; 9(5):531.

62 Matsumoto H, Hanayama H, Sakurai Y, Minami $\mathrm{H}$, Masuda $\mathrm{A}$, Tominaga $\mathrm{S}$, et al. Investigation of the characteristics of headache due to unruptured intracranial vertebral artery dissection. Cephalalgia. 2018 Aug;39(4):50414.

63 Goadsby PJ. Raeder's syndrome: paratrigeminal paralysis of the oculopupillary sympathetic system. J Neurol Neurosurg Psychiatry. 2002 Mar;72(3):297-9.

64 Siccoli MM, Bassetti CL, Sándor PS. Facial pain: clinical differential diagnosis. Lancet Neurol. 2006 Mar;5(3):257-67.

65 Colby CC, Del Gaudio JM. Stylohyoid complex syndrome: a new diagnostic classification. Arch Otolaryngol Head Neck Surg. 2011 Mar;137(3):248-52.

66 Gelfand AA, Johnson H, Lenaerts ME, Litwin JR, De Mesa C, Bogduk N, et al. Neck-Tongue syndrome: a systematic review. Cephalalgia. 2017 Feb;38(2):374-82.

67 Schiffman E, Ohrbach R, Truelove E, Look J, Anderson G, Goulet J-P, et al. Diagnostic criteria for temporomandibular disorders (DC/ TMD) for clinical and research applications: recommendations of the international RDC/ TMD Consortium Network* and orofacial pain special interest group $\dagger$. J Oral Facial Pain Headache. 2014;28(1):6-27.

68 LeResche L. Epidemiology of temporomandibular disorders: implications for the investigation of etiologic factors. Crit Rev Oral Biol Med. 1997;8(3):291-305.
69 Macfarlane TV, Glenny AM, Worthington HV. Systematic review of population-based epidemiological studies of oro-facial pain. J Dent. 2001 Sep;29(7):451.

70 Ahmad M, Schiffman EL. Temporomandibular joint disorders and orofacial pain. Dent Clin North Am. 2016 Jan;60(1):105-24.

71 Slade GD, Ohrbach R, Greenspan JD, Fillingim RB, Bair E, Sanders AE, et al. Painful temporomandibular disorder. J Dent Res. 2016 Sep;95(10):1084-92.

72 Anderson GC, John MT, Ohrbach R, Nixdorf DR, Schiffman EL, Truelove ES, et al. Influence of headache frequency on clinical signs and symptoms of TMD in subjects with temple headache and TMD pain. Pain. 2011 Apr;152(4):765-71.

73 Glaros AG, Urban D, Locke J. Headache and temporomandibular disorders: evidence for diagnostic and behavioural overlap. Cephalalgia. 2007 Jun;27(6):542-9.

74 Manfredini D, Winocur E, Guarda-Nardini L, Paesani D, Lobbezoo F. Epidemiology of bruxism in adults: a systematic review of the literature. J Orofac Pain. 2013;27(2):99-110.

75 Ballegaard V, Thede-Schmidt-Hansen P, Svensson P, Jensen R. Are headache and temporomandibular disorders related? A blinded study. Cephalalgia. 2008 Aug;28(8):832-41.

76 Gesch D, Bernhardt O, Kocher T, John U, Hensel E, Alte D. Association of malocclusion and functional occlusion with signs of temporomandibular disorders in adults: results of the population-based study of health in Pomerania. Angle Orthod. 2004 Mar;74(4): 512-20.

77 Gesch D, Bernhardt O, Alte D, Kocher T, John U, Hensel E. Malocclusions and clinical signs or subjective symptoms of temporomandibular disorders (TMD) in adults. Results of the population-based Study of Health in Pomerania (SHIP). J Orofac Orthop. 2004 Mar;65(2): 88-103.

78 Mujakperuo HR, Watson M, Morrison R, Macfarlane TV. Pharmacological interventions for pain in patients with temporomandibular disorders. Cochrane Database Syst Rev. 2010 Oct;(10):CD004715.

79 Fricton J, Look JO, Wright E, Alencar FGP, Chen $\mathrm{H}$, Lang M, et al. Systematic review and meta-analysis of randomized controlled trials evaluating intraoral orthopedic appliances for temporomandibular disorders. J Orofac Pain. 2010;24(3):237-54

80 McNeely ML, Armijo Olivo S, Magee DJ. A systematic review of the effectiveness of physical therapy interventions for temporomandibular disorders. Phys Ther. 2006 May;86(5) $710-25$.

81 List T, Axelsson S. Management of TMD: evidence from systematic reviews and meta-analyses. J Oral Rehabil. 2010 May;37(6):430-51.

82 Al-Jundi MA, John MT, Setz JM, Szentpétery A, Kuss O. Meta-analysis of treatment need for temporomandibular disorders in adult nonpatients. J Orofac Pain. 2008;22(2):97107.
83 Edens $\mathrm{MH}$, Khaled Y, Napeñas JJ. Intraoral pain disorders. Oral Maxillofac Surg Clin North Am. 2016 Aug;28(3):275-88.

84 Durham J, Nixdorf DR. Healthcare pathway and biopsychosocial impact of persistent dentoalveolar pain disorder: a qualitative study. Int Endod J. 2014 Dec;47(12):1151-9.

85 Nixdorf DR, Drangsholt MT, Ettlin DA, Gaul C, De Leeuw R, Svensson P, et al. Classifying orofacial pains: a new proposal of taxonomy based on ontology. J Oral Rehabil. 2012 Mar;39(3):161-9.

86 Brown JE. Salivary gland diseases: presentation and investigation. Prim Dent J. 2018 Mar;7(1):48-57.

87 Delli K, Spijkervet FKL, Vissink A. Salivary gland diseases: infections, sialolithiasis and mucoceles. Monogr Oral Sci. 2014 May;24: $135-48$.

88 Jääskeläinen SK. Is burning mouth syndrome a neuropathic pain condition? Pain. 2018 Mar;159(3):610-3.

89 Imura H, Shimada M, Yamazaki Y, Sugimoto K. Characteristic changes of saliva and taste in burning mouth syndrome patients. J Oral Pathol Med. 2016 Mar;45(3):231-6.

90 Lee YC, Hong IK, Na SY, Eun YG. Evaluation of salivary function in patients with burning mouth syndrome. Oral Dis. 2015 Apr;21(3): 308-13.

91 Spadari F, Venesia P, Azzi L, Veronesi G, Costantino D, Croveri F, et al. Low basal salivary flow and Burning Mouth Syndrome: new evidence in this enigmatic pathology. J Oral Pathol Med. 2015 Mar;44(3):229-33.

92 Poon R, Su N, Ching V, Darling M, Grushka $M$. Reduction in unstimulated salivary flow rate in burning mouth syndrome. Br Dent J. 2014 Oct;217(7):E14.

93 McMillan R, Forssell H, Buchanan JA, Glenny A-M, Weldon JC, Zakrzewska JM. Interventions for treating burning mouth syndrome. Cochrane Database Syst Rev. 2016 Nov;11 CD002779.

94 Ninan JV, Lester S, Hill CL. Giant cell arteritis: beyond temporal artery biopsy and steroids. Intern Med J. 2017 Nov;47(11):122840.

95 Gonzalez-Gay MA, Vazquez-Rodriguez TR, Lopez-Diaz MJ, Miranda-Filloy JA, Gonzalez-Juanatey C, Martin J, et al. Epidemiology of giant cell arteritis and polymyalgia rheumatica. Arthritis Rheum. 2009 Oct;61(10): 1454-61.

96 Hunder GG, Bloch DA, Michel BA, Stevens $\mathrm{MB}$, Arend WP, Calabrese LH, et al. The American College of Rheumatology 1990 criteria for the classification of giant cell arteritis. Arthritis Rheum. 1990 Aug;33(8):1122-8.

97 Caselli RJ, Hunder GG. Neurologic aspects of giant cell (temporal) arteritis. Rheum Dis Clin North Am. 1993 Nov [cited 2018 Feb 13]; 19(4):941-53.

98 Solomon S, Cappa KG. The headache of temporal arteritis. J Am Geriatr Soc. $1987 \mathrm{Feb}$ [cited 2018 Feb 13];35(2):163-5. 
99 Reiter S, Winocur E, Goldsmith C, EmodiPerlman A, Gorsky M. Giant cell arteritis misdiagnosed as temporomandibular disorder: a case report and review of the literature. J Orofac Pain. 2009;23(4):360-5.

100 Smith JH, Swanson JW. Giant cell arteritis Headache J Head Face Pain. 2014 Sep;54(8): 1273-89.

101 Labarca C, Koster MJ, Crowson CS, Makol A, Ytterberg SR, Matteson EL, et al. Predictors of relapse and treatment outcomes in biopsy-proven giant cell arteritis: a retrospective cohort study. Rheumatol (Oxford). 2015 Feb;55(2):347-56.

102 Stone JH, Tuckwell K, Dimonaco S, Klearman M, Aringer M, Blockmans D, et al. Trial of tocilizumab in giant-cell arteritis. $\mathrm{N}$ Engl J Med. 2017 Jul;377(4):317-28.

103 Schreiber CP, Hutchinson S, Webster CJ, Ames M, Richardson MS, Powers C. Prevalence of migraine in patients with a history of self-reported or physician-diagnosed "sinus” headache. Arch Intern Med. 2004 Sep;164(16):1769-72.
104 Eross E, Dodick D, Eross M. The sinus, allergy and migraine study (SAMS): CME. Headache J Head Face Pain. 2007 Feb; 47(2):213-24.

105 Levine H, Setzen M, Cady R, Dodick D, Schreiber $\mathrm{C}$, Eross E, et al. An otolaryngology, Neurology, allergy, and primary care consensus on diagnosis and treatment of sinus headache. Otolaryngol Head Neck Surg. 2006 Mar;134(3):516-23.

106 Akinci A, Güven A, Degerliyurt A, Kibar E, Mutlu M, Citirik M. The correlation between headache and refractive errors. J Am Assoc Pediatr Ophthalmol Strabismus. 2008 Jun;12(3):290-3.

107 Shindler KS, Sankar PS, Volpe NJ, Piltz-Seymour JR. Intermittent headaches as the presenting sign of subacute angle-closure glaucoma. Neurology. 2005 Sep;65(5):757-8
108 Nesher R, Mimouni MD, Khoury S, Nesher G, Segal O. Delayed diagnosis of subacute angle closure glaucoma in patients presenting with headaches. Acta Neurol Belg. 2014 Dec;114(4):269-72.

109 Mendrinos E, Machinis TG, Pournaras CJ. Ocular ischemic syndrome. Surv Ophthalmol. 2010 Jan;55(1):2-34.

110 Yangüela J, Sánchez-Del-Rio M, Bueno A, Espinosa A, Gili P, Lopez-Ferrando N, et al. Primary trochlear headache: a new cephalgia generated and modulated on the trochlear region. Neurology. 2004 Apr;62(7):1134-40.

111 Förderreuther S, Ruscheweyh R. From ophthalmoplegic migraine to cranial neuropathy. Curr Pain Headache Rep. 2015 Jun; 19(6):21.

112 La Mantia L, Curone M, Rapoport A, Bussone G, International Headache Society. Tolosa-Hunt syndrome: critical literature review based on IHS 2004 criteria. Cephalalgia. $2006 \mathrm{Jul} ; 26(7): 772-81$.

113 Zakrzewska JM. Differential diagnosis of facial pain and guidelines for management. $\mathrm{Br}$ J Anaesth. 2013;111(1):95-104. 